\title{
Measuring Grammatical Development in Bilingual Mandarin-English Speaking Children with a Sentence Repetition Task
}

\author{
Chai Ping Woon ${ }^{1}$, Ngee Thai Yap ${ }^{1}$, Hui Woan $\operatorname{Lim}^{2}$ \& Bee Eng Wong ${ }^{1}$ \\ ${ }^{1}$ Faculty of Modern Languages and Communication, University Putra Malaysia, Selangor, Malaysia \\ ${ }^{2}$ Faculty of Health Sciences, University Kebangsaan Malaysia, Kuala Lumpur, Malaysia \\ Correspondence: Ngee Thai Yap, Faculty of Modern Languages and Communication, Universiti Putra Malaysia, \\ 43400 UPM Serdang, Selangor, Malaysia. Tel: 60-3-8946-8673. E-mail: ntyap@upm.edu.my
}

Received: November 18, 2013 Accepted: July 7, $2014 \quad$ Online Published: August 14, 2014

doi:10.5539/jel.v3n3p144

URL: http://dx.doi.org/10.5539/jel.v3n3p144

\begin{abstract}
Sentence repetition (SR) tasks have been used to measure children's expressive language skills in normal and abnormal language development, and to examine the development of the speaking skills in second language acquisition, as well as to survey the proficiency of bilingual language development. Recently, SR tasks have been recognized as a potential psycholinguistic tool to identify bilingual children with language impairment. SR tasks are easy and quick to conduct, and a useful technique for obtaining quantitative and qualitative information about children's lexical and morphosyntactic knowledge, as well as language development in a complex linguistic background. This paper reports the results of a pilot study conducted to investigate the performance of SR among bilingual Mandarin-English preschoolers, from age four to six. The task was conducted in both languages: Mandarin, and English, to examine the type of grammatical errors found among different age groups in the SR task. Studying the performance of SR in both languages could provide a better understanding of children's language learning and their acquisition pattern in both the first and second language. Overall task accuracy in each language was compared; grammatical errors in the SR task were described qualitatively. The results showed that the linguistic characteristic of the stimulus materials in Mandarin and English influences the performance of these bilingual children in the SR task. The study also showed that the grammatical errors found in the SR tasks may have the potential of being used to distinguish children with typical and atypical language development in the first language (L1).
\end{abstract}

Keywords: grammatical development, bilingualism, second language acquisition, sentence repetition

\section{Introduction}

Children with Specific Language Impairment (SLI) are considered to have a language learning problem; they show language ability below the language skills expected for their age, but that is not caused by hearing impairment, neurological dysfunction, motor problems in producing speech, emotional or behavioral problems, autism, nor intellectual deficits as indicated in the literature (Stark \& Tallal, 1981; Leonard, 2000; Botting \& Conti-Ramsden, 2004). However, the protocol followed by speech language pathologist to identify such children involves the use of a battery of tests which includes a hearing screening test, articulation test, nonverbal IQ test, and language assessment in order to meet the inclusion and exclusion criteria (see Stalk \& Tallal, 1981; Leonard, 2000). The language assessment tool is only one of the tests used.

The process of identifying children at risk for SLI at an early age is challenging even among monolingual children. The problem is even more challenging in Malaysia as many Malaysian children are bilingual from a very young age, and most assessment tools that have been developed have been normed mainly on monolingual children and may not be suitable for identifying SLI among bilingual children. According to Ooi and Wong (2012), there are many cases of children in Malaysia with the potential risk of SLI who are not being identified because of the absence of a locally developed norm-referenced language assessment tool that can be used for bilingual children in Malaysia. In order to develop a suitable language assessment tool that caters directly to the bilingual children in Malaysia, we first need to have a firm understanding of the language development process of these bilingual children. This is the rationale for the study where we try to make a case for the potential use of a sentence repetition (SR) task as a potential language assessment tool to identify SLI among bilingual children. 
This paper reports a pilot study conducted to verify the suitability of the items constructed for two SR tasks - one in Mandarin and the other in English. The results of the pilot study show that the items for the Mandarin SR task were more sensitive to the language developmental curve of the bilingual children. However, the items for the English SR task were too difficult and were not useful in showing the language development of the children in acquiring English. The study also showed that the grammatical errors found in the SR tasks may have the potential of being used to distinguish children with typical and atypical language development in the L1.

\section{Literature Review}

Sentence repetition (SR) tasks which are also referred to as sentence recall or elicited imitation tasks, have been widely used to measure the expressive language skills among the normal developing children. This measure is used to ascertain the development of the speaking skills among children and older learners acquiring a second language, as well as to survey the level of bilingual language development and implicit L2 knowledge (e.g. Bley-Vroman \& Chaudron, 1994; Vinther, 2002; Erlam, 2006; Graham, Londsdale, Kennington, McGhee, \& Johnson, 2008; Weitze, McGhee, Graham, Dewey, \& Eggett, 2011; Wong \& Teo, 2012).

Recently, SR tasks have been increasingly recognized as a good indicator of abnormal language development. For example, SR tasks have been used to identify psycholinguistic markers to identify children with SLI among monolingual children (e.g. Conti-Ramsden, Botting, \& Faragher, 2001; Redmond, 2005; Stokes, Wong, Fletcher, \& Leonard, 2006; Archibald \& Joanisse, 2009; Seeff-Gabriel, Chiat, \& Dodd, 2010; Thordardottir \& Brandeker, 2012). The SR task is also a measurement tool used to identify children with autism, ADHD, and dyslexia. Previous studies (e.g. Alloway \& Gatthercole, 2005; Redmond, 2005; Riches, Loucas, Baird, Charman, \& Simonoff, 2010; Redmond, Thompson, \& Goldstein, 2011) have shown that the errors made by children with SLI differ from those made by children with autism, ADHD or dyslexia both qualitatively (error types) and quantitatively (frequency of errors).

SR is a task that requires participants to listen to a sentence and repeat it. To test the participants' ability, the test items include sentences of various lengths and complexities in the language that is being tested. The process of repeating a sentence heard involves various cognitive processes. When the participant hears the target sentence, he/she constructs an abstract representation of the sentence. This representation includes different levels of semantic information and the representation is maintained in the short-term memory. Then the participant utters a sentence based on the assessed representation (Bley-Vroman \& Chaudron, 1994, p. 247). As the sentences contain words that are syntactically linked, inflectional morphology, and semantic information, it would be reasonable to believe that SR might access not only the short-term memory (STM) but also the long-term memory (LTM).

Studies by Potter and Lombardi $(1990,1998)$ have shown that the LTM is involved in SR. Other studies (e.g. Slobin \& Welsh, 1973; Clay, 1971, cited in Riches et al., 2010) also show that an individual's ability to repeat an utterance, besides depending on the STM, necessitates the use of syntactic knowledge that resides in LTM to chunk the utterance so that the representation may be easy to retain and recall. Vinther (2002) further suggests that the participants will be able to repeat a sentence without any difficulties if they understand the sentence. If they understand the sentence but fail to remember it due to constraints in the STM, they may still produce a sentence with the same meaning, but in a form more or less similar to the original, as they are able to draw upon resources from the LTM. Previous studies (e.g. Lust, Chien, \& Flynn, 1987) have found that participants can employ their STM to recall and imitate a sentence accurately without understanding it if the sentence is short and grammatically simple enough. However, for longer sentences, participants cannot rely on their STM if they do not understand the sentence. Lust, Flynn and Foley (1996) argued that the sentence repeated is not a passive copy but a reconstruction of the sentence heard, and therefore reflects cognitive competence.

SR has increasingly received attention from researchers who view it as a potential tool to identify psycholinguistic markers that distinguishes children with or without SLI. In Conti-Ramsden et al. (2001), they suggest that SR in particular proved to be the most reliable tool. SR was found to have high sensitivity, specificity and overall accuracy rate. Several studies have found that SLI children perform poorly between their typically developing (TD) peers, and other clinical groups (e.g. Redmond, 2005; Stokes et al., 2006; Archibald et al., 2009; Seeff-Gabriel et al., 2010; Riches et al., 2010; Redmond et al., 2011; Thordardottir et al., 2012). Stokes et al. (2006) also found that SR has high specificity and sensitivity for identification of Cantonese SLI children. They found that SR is correlated with receptive grammar scores. These findings suggest that poor performance of SR may not be due to limitations in the STM but the influence of language ability. 
Besides providing a quantitative measure, the SR data can also be used qualitatively to provide insight into specific linguistic features that are difficult for SLI children and that distinguish them from their normal developing peers. According to Riches et al. (2010), children can make different types of error such as omission, replacement, addition of words, morphemes and phonemes, or a change in the word order when they perform the SR task. A qualitative analysis of the types of errors made with different syntactic structures will help researchers to identify potential linguistic markers that may serve as indicators of language delay or impairment.

According to the current understanding of SR, the assumption is that if the sentence is long enough, it would tax the participant's short-term memory, and consequently if the participant does not understand the sentence, he/she will not be able to repeat the sentence by rote. In other words, the more proficient language speakers are more able to repeat longer and more complex sentences. Therefore, we expect a difference in the performance of children in different age groups; the older children will perform better than the younger children. We expect children to perform better in the Mandarin SR task, their L1, compared to the English SR task, which is their L2.

\section{Method and Procedures}

A majority of children in Malaysia are bilingual or multilingual. Language contact between English and local languages have given rise to lexical borrowing, code-mixing and code-switching among Malaysians in their daily conversation (Baskaran, 2005). In Malaysia, each individual might have varying degrees of abilities in two or more languages (e.g. Mandarin-English, Malay-English, Hokkien-English, Mandarin-English-Malay, and Cantonese-Hokkien-Mandarin-Malay-English). Besides the nature of the multi-ethnic society with a large amount of languages, most Malaysians use their mother tongue in the home environment, such as Tamil, Mandarin or Cantonese and begin to learn English and Malay within the preschool ages. Lim (2010) argues that it may be difficult to correctly identify a specific language as the L1 among bilingual children who speak Mandarin and English at home from the local Chinese paediatric population.

In Malaysia, there are two types of institutions that cater to early childhood care and education: 1) childcare centres or nurseries that provide primarily child-care services and they usually take in children from as early as newborns to four year-olds; 2) preschools or kindergartens where children are prepared before enrolling to primary schools (Early childhood care \& Education, http://www.schoolmalaysia.com). Most children start nursery at an early age as both parents may be working and they start attending kindergarten between age four to six, where formal or semi-formal pre-school education is provided. Malaysian children start primary school education at age six or seven. The above factors were considered in selecting the children for the study.

\subsection{Participants of the Study}

In this pilot study, language samples were collected from 5 Chinese Malaysian children aged between 3.7-6.3. They were three girls and two boys: NNI, a girl, age 6.3; LYC, a boy, age 6.0; ZY, a girl, age 5.6; TT, a girl, age 4.0; and YZY, a boy, age 3.7. All of the children speak Mandarin as their first language (L1) and English as their second language (L2). They started going to nursery around the age of two. They are currently learning Mandarin, English, and Malay at the kindergarten. They speak Mandarin as the dominant home language, but English is also used at home. Following Ooi and Wong (2012), all children subjects selected for the study have at least 12 months of exposure to English at the nursery.

\subsection{Test Design}

SR task (English): The items of the English SR task were constructed based on suggestions from various studies (e.g. Gardner, McClelland, \& van der Lely, 2006; Riches \& Davis, 2009; Marinis, Chiat, Armon-Lotem, Piper, \& Roy, 2011; Armon-Lotem, 2013). The task consists of 20 sentences which assessed subject-verb agreement, tense-marking (past tense regular and irregular), copula-BE and auxiliary-BE, object question formation, articles, actional passive construction, prepositional phrases and phrasal embedding. These structures were selected to represent both simple and complex structures that may distinguish the various language development levels of bilingual children acquiring English as their L2. For example, a simple clause used in the SR task is The girl ran in the class; a complex clauses used in the task is The boy read a book when he sat down. The sentences contain approximately five to ten words, five to ten syllables in length, with a mean length of 7.9 syllables. In most of the SR assessment tools, the sentence length increases gradually. According to Riches \& Davis (2009), once children have warmed-up after repeating the shorter sentences, they would have a better chance to show their capability on longer sentences. Thus, in this study, the sequence of the sentences presented was based on their length, from the shortest to the longest.

SR task (Mandarin): The items of the Mandarin SR task were constructed based on existing literature (e.g. Stokes et al., 2006; Cheung. 2009; Yip \& Don, 2009; Li \& Thompson, 1989). Twenty sentences were 
constructed. These sentences were divided into 10 simple clauses and 10 complex clauses, which assessed the use of noun classifiers, and verb aspect markers. For example, a simple clause contains an aspect marker and a classifier:姐姐吃了两片面包 Jie3jie5 chil le5 liang3 pian4 mian4baol "Older sister ate two slices of bread"; while a complex clause consists of an independent clause and one or more dependent clauses: 妈妈要我在这等 她 Malma0 yao4 wo3 zai4 zhel deng3 tal "Mother wanted me to wait for her here". Each sentence that has an aspect marker also contains a noun classifier. The noun classifiers in this SR task are classifiers that are acquired at an early age (see Li, Huang, \& Hsiao, 2010). The sentences contain approximately six to eleven words in length, with a mean length of 8.3 words. Structures that are commonly used by children were selected; both simple and complex structures were targeted.

\subsection{Test Administration}

The children were tested individually in a quiet room at their home. The SR tasks in two languages-English and Mandarin were administered. All sessions were audio-recorded. Before each test, the children were given two examples to practice with. The children were told that they were going to hear some sentences. They were told to repeat exactly what they heard over the headphone. The stimulus sentences were recorded with a female voice. The children listened to the stimulus sentences presented on a laptop computer with a microphone headset and their responses were audio-recorded using a Sony ICD-UX513F Digital Voice Recorder. The children were allowed to hear each sentence only once. If the children do not repeat the sentence presented spontaneously, the researcher would pause the experiment and prompt them by asking them if they can repeat what they had heard or by asking them if they could remember what they had heard. The researcher would also praise the children for any attempt at repetition. If the child self-corrects, their final response would be taken regardless of whether the response is correct or incorrect. The children then move on to the next trial until the task is completed.

\subsection{Scoring}

Two scoring methods were adopted from Stokes et al. (2006) in this study. The first method is the complete sentence correct scoring method. Each sentence was assigned 1 point if the sentence was correctly repeated and 0 point if there were one or more errors, regardless of the type of error committed. The total score is 20 points for each language task. Any omission, addition, substitution were counted as errors. The purpose of the score is to give an overall view of the performance of each child. The second method used is a more structure- or feature-focused scoring method. A specific syntactic construction or morphosyntactic feature is identified for each sentence. A score of 1 is assigned if the participant correctly repeats the identified construction or feature and a zero is assigned if the error made involves the identified construction or feature.

\subsection{Data Analysis}

The overall accuracy on the SR task in each language was compared between the participants. In the context of this study, data extracted from the imitation response of children were examined for their linguistic structures which are deviant. Grammatical errors were described and their role as potential psycholinguistic marker of language delay is explored.

\section{Results and Discussion}

Overall, the results showed that the older children performed better than the younger children and the performance in the Mandarin SR task was also better compared to the English SR task. The results from the Mandarin SR task were found to be able to indicate the developmental stages of the bilingual children. The more complex features in Mandarin grammar were acquired at a later age. However, the items for the English SR task were not sensitive enough to show the language development of the bilingual children as most of the sentences were generally too difficult for all age groups. The following sections present the results of the two tasks in more detail.

\subsection{Mandarin Sentence Repetition Task}

Table 1 shows the overall performance of the children in the Mandarin SR Task. The results show that the older children (age 5 and 6 ) have acquired most of the structures tested in the task. They were able to repeat accurately simple clauses as well as the complex clauses. The errors made by the older children include addition of a numeral, substitution or addition of a lexical verb or classifier. For example, when the child was asked to repeat the simple clause in (1), LYC produced a similar sentence but with a different classifier as shown in (2). The classifer 本 ben 3 is used only with books, thus the sentence produced is ungrammatical in Mandarin. We will return to a discussion on the use of classifiers as errors with classifiers seem to be a potential marker of their developmental stages in Mandarin. 
(1) 妈妈穿着一双皮鞋

Ma1ma0 chuan1 zhe5 yil CLF-shuang1 pi2xie2

"Mother is wearing a pair of leather shoes."

(2) *妈妈穿着一本皮鞋

Ma1ma0 chuan1 zhe5 yi1 CLF-ben3 pi2xie2

Table 1. Raw scores for the Mandarin SR task

\begin{tabular}{llllll}
\hline Sentence type (N) & NNI (6;3) & LYC (6;0) & ZY (5;6) & TT (4;0) & YZY (3;7) \\
\hline Simple Clauses (8) & 8 & 7 & 8 & 5 & 1 \\
Complex Clauses (12) & 10 & 11 & 11 & 5 & 5 \\
Total & $\mathbf{1 8}$ & $\mathbf{1 8}$ & $\mathbf{1 9}$ & $\mathbf{1 0}$ & $\mathbf{6}$ \\
\hline
\end{tabular}

In the next example, when the child was asked to repeat a complex sentence as in (3), ZY produced it, as shown in (4), with an additional lexical verb which did not change the meaning of the sentence. The verb 出去 chulqu4 "go out" and 去 qu4 "go" presents approximately the same meaning in the sentence and are both grammatical in Mandarin. This example shows how the child is probably utilizing LTM in recalling the sentence.

(3) 姐姐叫我去外面玩

Jie3jie5 jiao4 wo3 qu4 wai4mian5 wan2

"Older sister asked me to play outside."

(4) 姐姐叫我出去外面玩

Jie3jie5 jiao4 wo3 chu1 qu4 wai4mian5 wan2

"Older sister asked me to go (out) outside to play."

However, the younger children made more errors for both the simple clauses as well as the complex clauses. The type of errors made by the younger children include errors which are typical errors such as substitution of classifiers (Cheung, Li, \& Barner, 2008) and aspect markers (Stokes \& Fletcher, 2003) and other errors which are likely to be also typical language development errors such as substitution of lexical verbs, omission of phrases, and simplification of complex sentences. However, our study also identified some potential atypical errors in word order and addition of functional items found with one child (see examples (11) and (13)).

Unlike the older group, the substitution errors made by the younger children may change the meaning of the utterance. For example, when repeating (5), TT substituted the aspect marker 在 zai4 with 了 le5, as shown in (6). This is expected as Cheung (2009) mentioned that the perfective aspect marker $了$ le5 is often acquired before other aspect markers such as progressive 在 zai4 and durative 着 zhe5 among children acquiring Mandarin as the first language.

（5）哥哥在穿一件衣服

Ge1ge5 zai4 chuan1 yi1 jian4 yilfu5

"Older brother is wearing a piece of clothing."

（6）哥哥穿了一件衣服

Ge1ge5 chuan1 le5 yi1 jian4 yilfu5

"Older brother wore a piece of clothing."

Younger children also produced simplified utterances which showed that LTM is involved in SR task. When repeating (7), TT's utterance as shown in (8) suggests that she understood the sentence but failed to recall it word for word; however she probably understood the original sentence as she simplified the sentence in a form that captures the meaning conveyed in the original version. However, when repeating the passive construction in (9), TT cannot rely on her LTM to recall longer sentences and the grammatical features of which she had not acquired, as shown in (10). Passives are reported to be acquired at a later age and less frequent in use in the literature (e.g. McEnery \& Xiao, 2005). The results show that the six-year-olds have already acquired the passives but not the four-year-olds. 
(7) 我有个哥哥很喜欢唱歌

Wo3 you3 ge4 ge1ge5 hen3 xi3huan1 chang4ge1

"I have a brother who likes singing very much."

(8) 我哥哥喜欢唱歌

wo3ge1ge5 xi3huan1 chang4 ge1

"My brother likes singing."

(9) 那本书被姐姐弄丢了

Na4 ben3 shu1 bei4 jie3jie5 nong4 diu1 le5

"That book was lost by my sister."

(10) 那本书

$\mathrm{Na} 4$ ben 3 shu1

"That book."

One interesting finding from the Mandarin SR task is the occurrence of atypical errors produced by the youngest participant in the study. In his attempt to repeat sentence (5), he produced a sentence with an atypical word order where the lexical verb is placed after the aspect marker as shown in (11). When repeating (12), he produced the same error, as shown in (13).

(11) *哥哥穿在一件的衣服

Ge1ge5 chuan1 zai4 yi1 jian4 de yilfu5

Older brother wear PROG one CLF DE clothing

(12) 妈妈读过这本书

Ma1ma5 du2 guo4 zhe4 ben3 shu1

Mother read ASP this CLF book

"Mother has read this book."

(13) *妈妈过读这本书

Ma1ma5 guo4 du2 zhe4 ben3 shu1

Personal communication with a number of Mandarin teachers and linguists suggests that this word order is not a typical error found among children acquiring Mandarin as L1. The errors he made were different qualitatively from the ones made by his peers. For example when YZY repeated sentence (7), he produced (14) which included addition of an atypical function words. Many of the sentences he repeated included the addition of 的 DE when it was not expected. We will show later that the child also produced atypical errors in the English SR task. However, at this point, we are unable to ascertain if this child has a language disorder or delay. Further investigation with the child would be necessary.

$(14) *$ * 我 有 哥哥的很喜欢唱歌

Wo3 you3 ge1ge5 de hen3 xi3huan1 chang4ge1

I have brother DE very like sing song

\subsection{English Sentence Repetition Task}

The final set of data was obtained from four participants instead of five. After completing the first two sentences, TT refused to continue with the task. The reason might be related to the difficulty of the sentences presented. Table 2 presents the overall performance of the children in repeating sentences with simple and complex structures in English. The results show that the performance was rather low even for the older children. They only repeated half of the simple sentences accurately.

Table 2. Raw scores for the English SR task

\begin{tabular}{lrrrrr}
\hline Sentence type (N) & NNI (6;3) & LYC (6;0) & ZY (5;6) & TT (4;0) & YZY (3;7) \\
\hline Simple (10) & 5 & 3 & 0 & - & 0 \\
Complex(10) & 3 & 1 & 0 & - & 0 \\
Total & $\mathbf{8}$ & 4 & $\mathbf{0}$ & - & $\mathbf{0}$ \\
\hline
\end{tabular}

However, when the errors were scrutinized, it was found that most of the errors made by the children involved omission of article, substitution of copula-BE verb with a related verb, and substitution of noun. The errors made by the older children include addition of an article, and substitution of a lexical verb. For example, when the 
child was asked to repeat the simple clause in (15), LYC produced a similar sentence but with addition of the definite article as shown in (16). Although a score of zero was awarded, most of the sentences were still grammatical and were semantically relevant. However, when the children repeated simple sentences with complex verb morphology like the one in (17), the sentences produced were not grammatical. For example, NNI produced it, as (18), with substitution of the auxiliary-BE with a word to fill in the gap. This type of error shows that with simple structures, the children could have used their LTM but with structures that involved more complex verb morphology, they may remember that a word is needed but they do not have the representation for it yet as passive structures are often acquired rather late (e.g. Hirsch \& Wexler, 2004; Kirby, 2010).

(15) The boys plant a tree at school.

(16) The boys plant a tree at the school.

(17) The tree was planted by the boy.

(18) The boy we planted by the boy.

With complex structures, even the older children had difficulty repeating them accurately. However, the type of errors produced by the older children was different than those produced by the younger children. Most of the children could not repeat sentences with centre-embedded relative clauses like (19). The sentences produced, shown in (20-21) suggest that they may not have understood the sentence either. It is clear that this structure is probably too difficult and may not be suitable for the SR task. The younger children could not even repeat much as shown in (22-23).

(19) The tree that the girl planted is small.

(20) The tree is girl planted with the small. (LYC)

(21) The tree that the girl planted is the girl. (NNI)

(22) The tree is "panted" is small. (YZY)

(23) The tree is "goed".... ahhh.... (ZY)

Similarly, with complex structures that involve subordination such as (24-25), the errors made by the older children involve substitution of the lexical verb or the subordinators as shown in (26-28). However, with younger children, they could hardly repeat anything as shown in (29-30). The errors found among the older children suggest that they were able to produce the independent clauses and the subordinate clauses but were not very successful in connecting them. They were probably utilizing their STM memory to recall the available slots in the sentence but were unable to produce a meaningful output as they probably have not acquired structures with subordination.

(24) The boy read a book when he sat down.

(25) The girl ate a cake before she went out.

(26) The boy want a book that he sat down. (LYC)

(27) The boy want a book when he sat down (NNI)

(28) The girl ate a cake so she cry down. (NNI)

(29) The boy and is bag the sit down (ZY)

(30) $\mathrm{mmm}$... the ate... the girl ... urr.. (ZY)

The younger children also made more omission and substitution errors which include typical errors such as substitution of article, omission of copula-BE, functional and lexical words, omission of phrases, simplification of complex sentences, as well as atypical errors in word order and addition of functional items. With ZY and TT, the utterances produced showed massive omissions probably due to the lack of proficiency in the L2. For example, when repeating the simple clause in (31), ZY produced it as (32), with omission of copula-BE. This seems to be a case of transfer from the L1as the structure in (32) is grammatical in Mandarin.

(31) The ball is under the table

(32) The ball under the table

The errors that were found can also be described as typical L2 learning errors and may not be indicative of language impairment or delay. In their meta-analysis study, Luk and Shirai (2009) examined Mandarin learners of English and found that the learners acquired plurals later than expected in the natural order hypothesis posited by Krashen (1977). The ESL learners had difficulty with the use of article, past tense verb forms and $3^{\text {rd }}$ person singular agreement. These morphosyntactic aspects of English grammar are usually acquired late by L2 learners. Such language problems may even persist among Malaysian Mandarin-English speaking adults as well as among other Malaysian English speakers as well. The local varieties of English, as described in Tongue (1974) and Baskaran (2005) particularly those belonging to the informal style are often characterized by structural variations that involve omission of the copula-BE (e.g. I say you good, you good la...), omission of -ing (I practice now), 
$-s$ agreement, and omission of preposition or use of preposition that would be considered ungrammatical in the standard variety (e.g. we go school, I go to school with bus).

Nicoladis, Song \& Marentette (2012) compared Chinese-English and French-English bilingual children in English past tense production. The results demonstrated that Chinese-English bilinguals made errors with regular verbs; they were more likely to use bare stem rather than the present tense, whereas French-English bilinguals used more present tense than bare stem. With irregular verbs, Chinese-English bilinguals used bare stem at a higher rate than overregularized forms, whereas French-English bilinguals showed a reverse pattern. The use of grammatical morphology as clinical marker to identify monolingual children with SLI has been widely accepted among SLI researchers; however, such clinical markers might not be applicable for bilingual Chinese-English children. Ooi and Wong (2012) argued that if bilingual children are assessed with the same assessment tools used to assess monolingual children; it is likely that bilingual children would be misdiagnosed as children with language delay. Given the persistent nature of such problems with older children and even the adult population, the errors found in the SR task cannot be taken as indications of language impairment nor language delay. Further work on refining the instrument for the English SR task needs to be undertaken. Nevertheless, the results from the SR task with one child did show the promise of the task in general as a suitable tool for identifying children with language difficulties. The errors produced by this child, YZY will be discussed below.

The youngest participant who was observed to produce atypical errors in mandarin was found to also produce atypical errors in the English SR task. Examples (33-35) are examples of utterances produced by YZY that illustrates this point. In his attempt to repeat sentence (33), he produced a sentence with an atypical word order where the lexical verb is placed before the subject. None of the other children produced such errors with these sentences.

(33) The girl ran in the class $\rightarrow$ The ran girl in the class.

(34) The boy is under the table $\rightarrow$ A ball I under the table.

(35) The boys plant a tree at school $\rightarrow$ The boy I p[1]anted the tree at school.

As YZY was rather young (3.7), the task was repeated two months later with a similar set of sentences and similar errors were still observed as shown in (36-38). The child omitted the subject but retained the article in (24) which is highly atypical. Children often omit the articles instead of the head noun for the subject. The child also seemed to be overusing a functional word, in this case the definite article as shown in (37-38). In the Mandarin SR task, it was the functional DE that was overused. It is not clear to us at the moment what to make out of these errors other than the fact that they are not typical errors as observed with other chidren.

(36) The girl carried a small bag $\rightarrow$ The carry small the bag.

(37) Which bag does Peter like? $\rightarrow$ Which the bag Peter like?

(38) Which cookie does Jane want? $\rightarrow$ Which cookie Jane the want?

In the next section, we will look at the performance of the participants in more detail to identify possible linguistic structures that can be used as psycholinguistic markers for language development delay or disorder. The results presented in this section involve a different coding method. Only errors pertaining to the identified structure were included in the scoring. Errors made to other aspects in the sentence were ignored. We will present the results from the Mandarin SR task first followed by the results from the English SR task.

\subsection{Linguistic Markers}

Three grammatical components in Mandarin: classifiers, aspect markers and complex sentences were selected for the Mandarin SR task. The selection was made following observations from Cheung (2009) who studied the grammatical development of Mandarin-speaking children with SLI as well as children with typical language development. He showed that these three aspects of the Mandarin grammatical system have the potential as linguistics markers for language impairment or delay. The items in the English SR task was found to be too difficult for the participants as discussed earlier and we could not see any potential linguistics markers unlike those found in the Mandarin SR data. Therefore, the discussion in this section will focus mainly on the data available from the Mandarin SR task.

The analysis of errors within sentences has provided information about language processing for children at different age groups. The older children used more substitution strategy to fill in the gap, whereas the younger children used the omission strategy more to recall the sentences; most of the time, however, they produced ungrammatical structures. As suggested by Clay (1971), a less proficient child, commonly with a limited memory span, would tend to reduce a longer sentence to a shorter one. Indeed, the stimuli used in this study were not originally designed to examine the order of language development in bilingual children; however, the errors 
found in the study could help us infer the children's acquisition pattern in both L1 and L2 according to the morphosyntactic targets examined in this study.

Table 3 and table 4 present the overall performance of the children in the Mandarin SR task. The results show that children of age 5 and 6 have completed their acquisition of the selected classifiers, aspect markers and complex structures featured in this study. Four types of aspect markers were examined in this study: perfective $-l e 5$, progressive -zai4, durative -zhe5, and experiential -guo4. According to Erbaugh (1992), perfective 了 le5 is the first one used by Mandarin speaking children. Progressive 在 zai4 and durative 着 zhe 5 usually emerged a month or two later. Experiential 过 guo4 is the last one to be acquired by children. In contrast, Xia (2009) found that the progressive 在 zai4 first appeared at 36 months, which is later than other aspect markers. In such case, this is quite similar to what we have found in this pilot study.

Table 3. Correct response (raw scores) of selected syntactic features in the Mandarin SR task

\begin{tabular}{llllll}
\hline Sentence structures (N) & $\begin{array}{l}\text { NNI } \\
(\mathbf{6 ; 3})\end{array}$ & $\begin{array}{l}\text { LYC } \\
\mathbf{( 6 ; 0 )}\end{array}$ & $\begin{array}{l}\mathbf{Z Y} \\
\mathbf{( 5 ; 6 )}\end{array}$ & $\begin{array}{l}\text { TT } \\
\mathbf{( 4 ; 0 )}\end{array}$ & $\begin{array}{l}\text { YZY } \\
\mathbf{( 3 ; 7 )}\end{array}$ \\
\hline Simple Structures with aspect markers: & & & & & \\
1. Durative 着-zhe5 (2) & 2 & 2 & 2 & 2 & 2 \\
2. Perfective 了-le5 (2) & 2 & 2 & 2 & 2 & 1 \\
3. Experiential 过-guo4 (2) & 2 & 2 & 2 & 2 & 0 \\
4. Progressive 在 -zai4 (2) & 2 & 2 & 2 & 1 & 0 \\
\hline Total & & $\mathbf{8}$ & $\mathbf{8}$ & $\mathbf{7}$ & $\mathbf{3}$ \\
\hline Complex Structure: & & & & & \\
5. Serial verb construction (2) & 2 & 2 & 2 & 2 & 2 \\
6. Clausal object (2) & 2 & 2 & 2 & 2 & 2 \\
7. Pivotal construction (2) & 2 & 2 & 2 & 2 & 1 \\
8. Passive (2) & 2 & 2 & 2 & 0 & 0 \\
9. Clausal subject (2) & 1 & 2 & 2 & 1 & 0 \\
10. Descriptive clausal (2) & 2 & 2 & 2 & 0 & 0 \\
\hline Total & $\mathbf{1 1}$ & $\mathbf{1 2}$ & $\mathbf{1 2}$ & $\mathbf{7}$ & $\mathbf{5}$ \\
\hline
\end{tabular}

Table 4. Correct response (raw scores) of selected classifiers in the Mandarin SR task

\begin{tabular}{llllll}
\hline Classifier & NNI (6;3) & LYC (6;0) & ZY (5;6) & TT (4;0) & YZY (3;7) \\
\hline -ben3 本(2) & 2 & 2 & 2 & 2 & 2 \\
-li4 粒(1) & 1 & 1 & 1 & 1 & 1 \\
-kuai4 块(1) & 1 & 1 & 1 & 1 & 1 \\
-jian4 件(1) & 1 & 1 & 1 & 1 & 1 \\
-ding3 顶(2) & 2 & 2 & 2 & 1 & 2 \\
-ba3 把(1) & 1 & 1 & 1 & 1 & 1 \\
-zhi1 只(1) & 1 & 1 & 1 & 1 & 0 \\
-pian4 片(1) & 1 & 1 & 1 & 1 & 0 \\
-ke1 颗(1) & 1 & 1 & 1 & 0 & 0 \\
-tai2 台(1) & 1 & 1 & 1 & 0 & 1 \\
-ge4 个(1) & 1 & 1 & 1 & 0 & 0 \\
-shuang1 双(1) & 1 & 0 & 1 & 0 & 0 \\
Total & $\mathbf{1 4}$ & $\mathbf{1 3}$ & $\mathbf{1 4}$ & $\mathbf{9}$ & $\mathbf{9}$ \\
\hline
\end{tabular}


Table 5. Distribution of correct responses across different types of sentence structures in the English SR task

\begin{tabular}{|c|c|c|c|c|c|}
\hline Sentence structures $(\mathbf{N})$ & $\begin{array}{l}\text { NNI } \\
(6 ; 3)\end{array}$ & $\begin{array}{l}\text { LYC } \\
(\mathbf{6 ; 0 )}\end{array}$ & $\begin{array}{l}Z Y \\
(5 ; 6)\end{array}$ & $\begin{array}{l}\text { TT } \\
(4 ; 0)\end{array}$ & $\begin{array}{l}\text { YZY } \\
(3 ; 7)\end{array}$ \\
\hline \multicolumn{6}{|l|}{ Simple Structure (10) } \\
\hline 1. Irregular past tense (2) & 1 & 1 & 1 & - & 1 \\
\hline 2. Regular past tense (2) & 2 & 1 & 0 & - & 0 \\
\hline \multicolumn{6}{|l|}{ 3. Subject verb agreement } \\
\hline : Copula -Be (2) & 2 & 1 & 0 & - & 0 \\
\hline$: 3^{\text {rd }}$ person singular/plural (2) & 1 & 1 & 1 & - & 0 \\
\hline : Auxiliary -Be (2) & 0 & 0 & 1 & - & 0 \\
\hline Total & 6 & 4 & 3 & - & 1 \\
\hline \multicolumn{6}{|l|}{ Complex Structure: } \\
\hline 1. Wh-Object Which question (2) & 2 & 1 & 1 & - & 0 \\
\hline 2. Actional passive (2) & 2 & 1 & 0 & - & 0 \\
\hline 3. Relative clause -right branching (2) & 1 & 0 & 0 & - & 0 \\
\hline 4. Adjunct clause (2) & 0 & 0 & 0 & - & 0 \\
\hline 5. Centre embedded clause (2) & 0 & 0 & 0 & - & 0 \\
\hline Total & 5 & 2 & 1 & - & $\mathbf{0}$ \\
\hline
\end{tabular}

It would be more difficult to derive the pivotal construction, as shown in (39) compared to the serial verb construction, which is monoclausal. YZY had difficulty in deriving sentences with the pivotal construction; he reduced the pivotal construction into a monoclausal structure by omitting the noun phrase which serves as an object and a subject, as shown in (40), which gives a meaning different from the original sentence.

(39) 妈妈要我在这里等她

Ma1ma5 yao4 wo3 zai4 zhe4 li3 deng3 ta1

"Mother wanted me to wait for her here."

(40) 妈妈在 这里等她

Ma1ma5 zai4 zhe4 li3 deng3 ta1

"Mother waits for her here."

The performance of YZY, who is only six months younger than TT, is rather different as discussed earlier, and therefore may not be representative of what children at age 3 or 4 may be capable of. Nevertheless, it is interesting to note that YZY had difficulty with aspect markers in a different way compared to his peer, TT.

Table 5 presents the performance of the children according to the types of structure selected for the English SR task. As evident in Table 5, centre embedded clauses and adjunct clauses are the most difficult for Mandarin-English bilingual children. Relative clauses that are right branching rank next in terms of level of difficulty. In this study, the English SR result showed low performance of children in their L2. It is common that children have lower performance in their L2 compared to their L1. If we only assess children's language ability in the L2, we might not be able to accurately assess children's language problems. With the L1 SR test, uncommon errors or structures found would enable us to evaluate a child's performance across languages. The task would help us to determine if a child has language problems in only one language or in both languages. Chiat et al. (2012) suggested that it would be preferable that children be assessed using L1 and L2 SR tests to evaluate the consistency of children's performance across languages.

In sum, the results show that the sentences designed in the English SR task in this study are too difficult for the preschool children. The children were not able to perform well even with the simple structures. The items for the English SR task were not sensitive enough to show the language development curve among these children. Revision for these items would be needed to improve the sensitivity of the items to the children's level of development in the second language. However, the items for the Mandarin SR task seem to be appropriate and may be sensitive enough to show the language development stage of the bilingual children in Mandarin. 


\section{Conclusion and Recommendations}

In conclusion, the pilot study showed that SR is an easy task to conduct, and it is a useful tool to obtain quantitative and qualitative information about bilingual children's lexical and morphosyntactic knowledge, as well as language development level in a complex linguistic background. The result showed that the linguistic characteristic of the stimulus materials in Mandarin and English influences the performance of these bilingual children in the SR task. The bilingual children performed better in the Mandarin SR task. Performance of the children in the Mandarin SR task was found to indicate the developmental stages of the bilingual child in Mandarin. The more complex features in Mandarin grammar were acquired at a later age. Passive constructions, for example, were acquired by older children. The five- and six-year-olds seem to have acquired most of the Mandarin structures tested in the task. Children of age 5 and 6 seem to have completed their acquisition of the selected classifiers, aspect markers and complex structures featured in this study. The selected aspectual markers: perfective -le5, progressive -zai4, durative -zhe5, and experiential -guo4 seem to pose little difficulty even for the youngest children. Some classifiers, however, such as 颗 ke1, 台 tai2, and 双 shuangl, may be difficult for the younger children.

In constrast, the items for the English SR task were not sensitive enough. A lot of the errors found were also common among adult L2 learners and have been described as features of L2 interlanguage grammar of L2 learners. The children also found most of the complex structures difficult to repeat. Almost all the children had difficulty with centre-embedded relative clauses. Further modification of the English SR task is needed in order to have a better refined test to evaluate preschool children's L2 language development. From the result, we found that children have difficulty in repeating the second subject with the definite article -the, this might be due to the fact that the article system does not exist in Mandarin. We, therefore, recommend changing the article -the + noun to proper nouns (e.g. Peter, Jane) or nouns that are usually acquired early (e.g. cookie, toy, cat). The complex strucutres in the English SR task were too difficult, for example, the centre embedded clauses. The centre embedded clauses can be replaced by complement clauses, which are more familiar to the children.

The study also showed that the grammatical errors found in the SR tasks may have the potential of being used to distinguish children with typical and atypical language development. Classifiers, aspectual markers and passive construction hold this potential for Mandarin. More research needs to be done with the English sentence sets before any conclusive decisions can be made. It should also be noted that the pilot study reported in this study involved only a few children. Further studies involving more children are needed to validate the results further to determine the suitability of the test sentences and grammatical features that were selected in the SR task for both Mandarin and English.

\section{References}

Alloway, T. P., \& Gathercole, S. E. (2005). The role of sentence recall in reading and language skills of children with learning difficulties. Learning and Individual Differences, 15(4), 271-282. http://dx.doi.org/10.1016/j.lindif.2005.05.001

Archibald, L. M. D., \& Joanisse, M. F. (2009). On the sensitivity and specificity of nonword repetition and sentence recall to language and memory impairments in children. Journal of Speech, Language, and Hearing Research, 52(4), 899-914. http://dx.doi.org/10.1044/1092-4388(2009/08-0099)

Armon-Lotem, S. (2013). Between L2 and SLI: Inflections and prepositions in the Hebrew of bilingual children with TLD and monolingual children with SLI. Journal of Child Language, 41, 3-33. http://dx.doi.org/10.1017/S0305000912000487

Baskaran, L. M. (2005). A Malaysian English primer: Aspects of Malaysian English features. Kuala Lumpur: University of Malaya Press.

Bley-Vroman, R., \& Chaudron, C. (1994). Elicited imitation as a measure of second-language competence. In E. Tarone, S. Gass, \& A. Cohen (Eds), Research methodology in second-language acquisition (pp. 245-226). New Jersey: Lawrence Erlbaum.

Botting, N., \& Conti-Ramsden, G. (2004). Characteristics of children with specific language impairment. In L. Verhoeven, \& H. van Balkom (Eds.), Classification of developmental language disorders: Theoretical issues and clinical implications (pp. 23-38). Mahwah, NJ: Lawrence Erlbaum Associates.

Cheung, H. T (2009). Grammatical characteristics of Mandarin-speaking children with specific language impairment. In S. P. Law, B. S. Weekes, \& Anita. M. Y. Wong (Eds), Language Disorders in Speakers of Chinese (pp. 33-52). Multilingual Matters. 
Cheung, P., Li, P., \& Barner, D. (2008). Sources of individuation in Mandarin Chinese, a classifier language. $22^{\text {nd }}$ Pacific Asia Conference on Language, Information and Computation (pp. 151-160).

Chiat, S., Armon-Lotem, S., Marinis, T., Polišenská, K., Roy, P., \& Seeff-Gabriel, B. (2012). The potential of sentence imitation tasks for assessment of language abilities in sequential bilingual children. In V. C. M. Gathercole (Ed.), Bilinguals and assessment: State of the art guide to issues and solutions from around the world. Multilingual Matters.

Clay, M. M. (1971). Sentence repetition: Elicited imitation of a controlled set of syntactic structures by four language groups. Monographs of the Society for Research in Child Development, 36(3), 1-85. http://dx.doi.org/ 10.2307/1165821

Conti-Ramsden, G., Botting, N., \& Faragher, B. (2001). Psycholinguistic markers for specific language impairment (SLI). The Journal of Child Psychology and Psychiatry and Allied Disciplines, 42(6), 741-748. http://dx.doi.org/10.1111/1469-7610.00770

Erbaugh, M. (1992). The acquisition of Mandarin. In D. I. Slobin (Ed.), The crosslinguistic study of language acquisition (Vol. 3, pp. 373-456). Mahwah, NJ: Lawrence Erlbaum.

Erlam, R. (2006). Elicited imitation as a measure of L2 implicit knowledge: An empirical validation study. Applied Linguistics, 27, 464-491. http://dx.doi.org/10.1093/applin/aml001

Gardner, H., McClelland, A., \& van der Lely, H. K. J. (2006). Development of the grammar and phonology screening (GAPS) test to assess key markers of specific language and literacy difficulties in young children. International Journal of Language and Communication Disorders, 41(5), 513-540. http://dx.doi.org/10.1080/13682820500442644

Graham, C. R., Londsdale, D., Kennington, C., Johnson, A., \& McGhee, J. (2008). Elicited imitation as an oral proficiency measure with ASR scoring. Proceedings of LREC 2008.

Hirsch, C., \& Wexler, K. (2004). Children's passives and their resulting interpretation. Paper presented at GALANA, 2004, University of Hawai'I at Manoa.

Kirby, S. (2010). Passives in first language acquisition: what causes the delay? University of Pennsylvania Working Papers in Linguistics, 16(1), 13. Retrieved from http://repository.upenn.edu/pwpl/vol16/iss1/13

Krashen, S. (1977). Some issues relating to the Monitor Model. In H. Brown, C. Yorio, \& R. Crymes (Eds.), On TESOL'77 (pp. 144-158). Washington, DC: TESOL.

Leonard, L. B. (2000). Children with specific language impairment. Cambridge, MA: MIT Press. First MIT Press paperback edition.

Li, C. N., \& Thompson, S. A. (1989). Mandarin Chinese: A functional reference grammar. University of California Press, Ltd.

Li, P., Huang, B., \& Hsiao, Y. (2010). Learning that classifiers count: Mandarin-speaking children's acquisition of sortal and mensural classifiers. Journal of East Asian Linguist, 19, 207-230. http://dx.doi.org/10.1007/s10831-010-9060-1

Lim, H. W. (2010). Phonological Acquisition in Three Languages: A Cross-Sectional Study of English, Mandarin and Malay. PhD thesis: University of Sheffield, UK.

Luk, Z. P. S., \& Shirai, Y. (2009). Is the acquisition order of grammatical morphemes impervious to L1 knowledge? Evidence from the acquisition of plural-s, articles, and possessives. Language Learning, 59(4), 721-754. http://dx.doi.org/ 10.1111/j.1467-9922.2009.00524.x

Lust, B., Chien, Y., \& Flynn, S. (1987). What children know: Methods for the study of first language acquisition. In B. Lust (Ed.), Studies in the acquisition of anaphora (vol. II, pp. 271-356). Dordrecht: D. Reidel Publishing Company.

Lust, B., Flynn, S., \& Foley, C. (1996). What children know about what they say: Elicited imitation as a research method for assessing children's syntax. In D. McDaniel, C. McKee., \& H. S. Cairns (Eds), Methods for assessing children's syntax language, speech, and communication (pp. 55-76). MIT Press.

Manisah, M. A. (2005). Phonological awareness of Malaysian bilingual children. Malaysian Journal of ELT Research. Retrieved from http://www.melta.org.my/modules/tinycontent/Dos/manisah_melta journal_2005.pdf 
Marinis, T., Chiat, S., Armon-Lotem, S., Piper, \& Roy, P. (2011). School-age sentence imitation test-E32. Retrieved from http://www.city.ac.uk

McEnery, A., \& Xiao, Z. (2005). Passive constructions in English and Chinese: A corpus-based contrastive study. In Proceedings of Corpus linguistics 2005. Birmingham University. Retrieved from http://eprints.lancs.ac.uk/63/1/CL2005_\%2822\%29_-_passive_paper_-_McEnery_and_Xiao.pdf

Nicoladis, E., Song, J. H., \& Marentette, P. (2012). Do young bilinguals acquire past tense morphology like monolinguals, only later? Evidence from French-English and Chinese-English bilinguals. Applied Psycholinguistics, 33(3), 457-479. http://dx.doi.org/10.1017/S0142716411000439

Ooi, C. C. W., \& Wong, A. M. Y. (2012). Assessing bilingual Chinese-English young children in Malaysia using language sample measures. International Journal of Speech-Language Pathology, 14(6), 499-508. http://dx.doi.org/ 10.3109/17549507.2012.712159

Potter, C. M., \& Lombardi, L. (1990). Regeneration in the short term recall of sentences. Journal of Memory and Language, 29, 633-654. http://dx.doi.org/10.1016/0749-596X(90)90042-X

Potter, C. M., \& Lombardi, L. (1998). Syntactic priming in immediate recall of sentences. Journal of Memory and Language, 38, 265-282. http://dx.doi.org/10.1006/jmla.1997.2546

Redmond, S. M. (2005). Differentiating SLI from ADHD using children's sentence recall and production of past tense morphology. Clinical Linguistics \& Phonetics, 19(2), 109-127. http://dx.doi.org/10.1080/02699200410001669870

Redmond, S. M., Thompson, H. L., \& Goldstein, S. (2011). Psycholinguistics profiling differentiates specific language impairment from typical development and from attention-deficit/hyperactivity disorder. Journal of Speech, Language, and Hearing Research, 54, 99-117. http://dx.doi.org/10.1044/1092-4388(2010/10-0010)

Riches, N. G., \& Davis, K. (2009). Qualitative assessment of sentence repetition. Retrieved from http://www.reading,ac.uk/pcls/research/cls-quasr.aspx

Riches, N. G., Loucas, T., Baird, G., Charman, T., \& Simonoff, E. (2010). Sentence repetition in adolescents with specific language impairment and autism: An investigation of complex syntax. International Journal of Language \& Communication Disorders, 45(1), 47-60. http://dx.doi.org/10.3109/13682820802647676

Seeff-Gabriel, B., Chiat, S., \& Dodd, B. (2010). Sentence imitation as a tool in identifying expressive morphosyntactic difficulties in children with severe speech difficulties. International Journal of Language \& Communication Disorder, 45(6), 691-702. http://dx.doi.org/10.3109/13682820903509432

Slobin, C. A., \& Welsh, C. A. (1973). Elicited imitation as a research tool in developmental psycholinguistics. In C. A. Ferguson, \& D. I. Slobin (Eds), Studies in child language development (pp. 485-497). New York: Holt, Rinehart and Winston, Inc.

Stark, R. E., \& Tallal, P. (1981). Selection of children with specific language deficits. Journal of Speech and Hearing Disorders, 46, 114-122. http://dx.doi.org/10.1044/jshd.4602.114

Stokes, S., \& Fletcher, P. (2003). Aspectual forms in Cantonese children with specific language impairment. Linguistics, 41(2), 381-405. http://dx.doi.org/10.1515/ling.2003.013

Stokes, S., Wong, Anita M. Y., Flecther, P., \& Leonard, L. B. (2006). Nonword repetition and sentence repetition as clinical markers of specific language impairment: The case of Cantonese. Journal of Speech, Language, and Hearing Research, 49(2), 219-236. http://dx.doi.org/10.1044/1092-4388(2006/019)

Thordardottir, E., \& Brandeker, M. (2012). The effect of bilingual exposure versus language impairment on nonword repetition and sentence imitation scores. Journal of Communication Disorders, 46(1), 1-16. http://dx.doi.org/10.1016/j.jcomdis.2012.08.002.

Tongue, R. K. (1974). The English of Singapore and Malaysia. Eastern Universities Press.

Vinther, T (2002). Elicited imitation: A brief review. International Journal of Applied Linguistics, 12, 54-73. http://dx.doi.org/10.1111/1473-4192.00024

Weitze, M., McGhee, J., Graham, C. R., Dewey, D. P., \& Eggett, D. L. (2011). Variability in L2 acquisition across L1 backgrounds (pp. 152-163). Selected Proceedings of the 2009 Second Language Research Forum.

Wong, B. E., \& Teo, P. H. L. (2012). Elicited imitation as a measure of L2 English learners' interlanguage representation of relative clauses. Electronic Journal of Foreign Language Teaching, 9(1), 91-107. 
Yip, P. C., \& Don, R. (2009). Basic Chinese: a grammar and workbook (2nd ed.). Routledge: Taylor \& Francis Group.

\section{Copyrights}

Copyright for this article is retained by the author(s) with first publication rights granted to the journal.

This is an open-access article distributed under the terms and conditions of the Creative Commons Attribution licence (http://creativecommons.org/licenses/by/3.0) 